\title{
Prior vaginal delivery is a predictive factor affecting success in trial of labor after cesarean section
}

To the Editor,

I have read with great interest the article entitled "Maternal and obstetrical factors associated with a successful trial of vaginal birth after cesarean section" by Abdelazim et al. (1) that was published in the previous issue of the Journal of the Turkish German Gynecological Association. In this article, the authors brought to our attention the significance of distinct risk factors that could affect the outcome of a trial of labor after cesarean section (TOLAC). Although the report by Abdelazim and coworkers confirms findings from previous studies, I would like to include some considerations on the subject.

The objective of this study was to evaluate the risk factors associated with TOLAC, but the authors seem to overlook one important factor related to the results of this study. Previous history of vaginal delivery before cesarean section is not defined by the authors. The predictive role of prior vaginal delivery is strictly related to the outcomes of TOLAC and may require further clarification and discussion.

TOLAC is an important strategy to limit repeat cesarean sections and the complications related to the procedure. Although maternal morbidity in women with previous cesareans is higher when TOLAC fails, identifying the optimal patient who would attain maximum benefit is crucial. For this reason, determining risk factors before deciding whether the patient can undergo TOLAC or repeat cesarean section is important for the obstetrician. In the process of decision-making, it must be noted that patients with a prior vaginal delivery have higher rates of successful vaginal births after cesarean (VBAC) than patients without a prior vaginal birth (2).

Although evaluation of individual risks is important in determining who are appropriate candidates for TOLAC, the American College of Obstetricians and Gynecologists (ACOG) (3) defines prior vaginal birth and spontaneous labor as a strong predictor for TOLAC success. In view of this data, Grobman et al. (4) were the first to report the most utilized and validated model for predicting the probability of successful TOLAC. In this model, it is demonstrated that vaginal delivery and prior VBAC are the two characteristics that are useful for predicting successful TOLAC. These findings also have been repeatedly validated by multiple studies (5).

\author{
Fatma Beyazit \\ Clinic of Obstetrics and Gynecology, Çanakkale State Hospital, \\ Çanakkale, Turkey
}

\section{References}

1. Abdelazim IA, Elbiaa AA, Al-Kadi M, Yehia AH, Sami Nusair BM, Faza MA. Maternal and obstetrical factors associated with a successful trial of vaginal birth after cesarean section. J Turk Ger Gynecol Assoc 2014; 15: 245-9. [CrossRef]

2. Sentilhes L, Vayssière C, Beucher G, Deneux-Tharaux C, Deruelle P, Diemunsch P, et al. Delivery for women with a previous cesarean: guidelines for clinical practice from the French College of Gynecologists and Obstetricians (CNGOF). Eur J Obstet Gynecol Reprod Biol 2013; 170: 25-32. [CrossRef]

3. American College of Obstetricians and Gynecologists. ACOG Practice bulletin no. 115: Vaginal birth after previous cesarean delivery. Obstet Gynecol 2010; 116(2 Pt 1): 450-63.

4. Grobman WA, Lai Y, Landon MB, Spong CY, Leveno KJ, Rouse DJ, et al. Development of a nomogram for prediction of vaginal birth after cesarean delivery. Obstet Gynecol 2007; 109: 806-12. [CrossRef]

5. Tessmer-Tuck JA, El-Nashar SA, Racek AR, Lohse CM, Famuyide AO, Wick MJ. Predicting vaginal birth after cesarean section: a cohort study. Gynecol Obstet Invest 2014; 77: 121-6. [CrossRef]

\section{Author's Response}

I would like to thank the authors for their valuable comments on our study.

We entirely agree with the authors that previous vaginal delivery prior cesarean section influences the outcomes of trial of labor after cesarean section (TOLAC) and patients with previous vaginal delivery have higher rates of successful vaginal birth after cesarean section (VBAC), (1).

Also, American College of Obstetricians and Gynecologists defined prior vaginal birth and spontaneous labor as strong predictors for the success of TOLAC (2).

Women with one previous lower segment cesarean section for non-recurrent cause for cesarean section, without severe medical disorders, a singleton pregnancy with cephalic presentation, a clinically estimated fetal weight of $\leq 3.5 \mathrm{~kg}$, an adequate pelvis and in spontaneous labor in the absence of maternal or fetal compromise, and who were willing to undergo the trial of a scar were included in Abdelazim et al's study (3). In addition, 
importance of spontaneous labor pains before TOLAC was mentioned in Raja and colleagues' study (4).

Item of previous vaginal birth was not included in Abdelazim et al. (3) study for two reasons: 1. Women with only one delivery by cesarean section without any prior vaginal birth were willing to be included in our study, and, 2. If there was no history of prior vaginal birth before TOLAC, a clinically estimated fetal weight of $\leq 3.5 \mathrm{~kg}$ and adequate maternal pelvis can replace prior vaginal birth.

Moreover, clinical estimation of the fetal weight and assessment of maternal pelvic capacity adds to the health provider's clinical experience.

Ibrahim A. Abdelazim

Department of Obstetrics and Gynecology, Ain Shams University, Cairo, Egypt and Ahmadi Hospital, Kuwait Oil Company, Kuwait

\section{References}

1. Sentilhes L, Vayssière C, Beucher G, Deneux-Tharaux C, Deruelle P, Diemunsch P, et al. Delivery for women with a previous cesarean: guidelines for clinical practice from the French College of Gynecologists and Obstetricians (CNGOF). Eur J Obstet Gynecol Reprod Biol 2013; 170: 25-32. [CrossRef]

2. American College of Obstetricians and Gynecologists. ACOG Practice bulletin no. 115: Vaginal birth after previous cesarean delivery. Obstet Gynecol 2010; 116(2 Pt 1): 450-63.

3. Abdelazim IA, Elbiaa AA, Al-Kadi M, Yehia AH, Sami Nusair BM, Faza MA. Maternal and obstetrical factors associated with a successful trial of vaginal birth after cesarean section. J Turk Ger Gynecol Assoc 2014; 15: 245-9. [CrossRef]

4. Raja JF, Bangash KT, Mahmud G. VBAC scoring: successful vaginal delivery in previous one caesarean section in induced labour. J Pak Med Assoc 2013; 63: 1147-51. 